\title{
Comunicação
}

[Communication]

\section{Resistência bacteriana e ação das bacteriocinas de Lactobacillus spp em Staphylococcus aureus isolados de mastite bovina}

\author{
[Bacterial resistance and bacteriocins action in Staphylococcus aureus isolated \\ from bovine mastitis] \\ B.R. Pribul ${ }^{1}$, I.A. Pereira ${ }^{1}$, L.C. Soares ${ }^{1}$, S.M.O. Coelho ${ }^{2}$, I.L. Barberis ${ }^{3}$, \\ L. Pascual ${ }^{3}$, M.M.S. Souza ${ }^{2 *}$ \\ ${ }^{1}$ Alunos de pós-graduação-IV- UFRRJ-Seropédica,RJ \\ ${ }^{2}$ Instituto de Veterinária da UFRRJ-Seropédica,RJ \\ ${ }^{3}$ Universidade Nacional de Rio Cuarto - Córdoba, Argentina
}

No Brasil, os Staphylococcus aureus são comumente recuperados das amostras de leite de vacas com mastite (Moraes et al., 2004) sendo um dos mais significativos patógenos causadores de infecções intramamárias no gado leiteiro em todo o mundo (Aarestrup et al., 2001). Em décadas mais recentes, uma dificuldade adicional no controle da infecção por este agente é representada por sua freqüente resistência aos antimicrobianos.

Dentre os fármacos utilizados nas infecções estafilocócicas, os $\beta$-lactâmicos são mais freqüentes. Seu mecanismo de ação consiste na inibição de enzimas com função de transpeptidases, que atuam nas etapas finais da formação da parede celular das bactérias, conhecidas como penicillin binding protein (PBP). Vários trabalhos vêm relatando a disseminação de cepas resistentes, nas quais a produção de $\beta$-lactamases e modificação das PBPs são os mais importantes mecanismos descritos (Aarestrup et al. 2001). A produção da PBP2a, proteína de ligação à penicilina de baixa afinidade, é determinada pela presença do gene mecA (Moon et al. 2007).

O objetivo deste trabalho foi investigar o perfil de resistência antimicrobiano de isolados de Staphylococcus aureus a partir de mastite bovina e avaliar a sensibilidade destes isolados a bacteriocinas produzidas por cepas de Lactobacillus spp.

Recebido em 28 de janeiro de 2011

Aceito em 13 de abril de 2011

*Autor para correspondência (corresponding author)

E-mail:miliane@ufrrj.br
Para isso 25 propriedades leiteiras situadas na região Sul Fluminense e adjacências do Estado do Rio de Janeiro foram analisadas quanto à presença de mastite. Imediatamente antes da ordenha, foi realizado o California Mastitis Test (CMT), e segregação dos animais considerados positivos. Seus tetos foram lavados com água e sabão neutro e secados com papel toalha para a coleta da amostra de leite, por ordenha manual, em tubo de ensaio estéril. Foram coletadas amostras de 137 animais positivos no teste.

O procedimento de isolamento e identificação foi desenvolvido segundo Koneman et al (2008). As amostras foram inoculadas em ágar-sangue de carneiro a 5\%. Posteriormente, as colônias sugestivas de Staphylococcus foram repicadas em ágar seletivo manitol vermelho de fenol e submetidas ao protocolo de identificação pertinente considerando características morfotintoriais, produção de catalase e coagulase livre, produção de acetoína, redução de nitratos e fermentação de açúcares. A confirmação da espécie S.aureus foi realizada por meio da amplificação de genes específicos e do DNA ribossomal (Coelho et al., 2007)

A suspensão bacteriana utilizada para os testes foi preparada por meio de inoculação de colônias isoladas em caldo Müeller-Hinton (MH),

incubadas por 18 horas a $37^{\circ} \mathrm{C}$ e diluídas na concentração do tubo 0,5 da escala de Mc 
Farland, equivalente a $1,5 \times 10^{6}$ células/mL. O perfil da atividade inibitória da penicilina, oxacilina, vancomicina, ampicilina, e da associação ampicilina e sulbactam foi analisado para todos os isolados em ágar $\mathrm{MH}$ por 24 horas a $37^{\circ} \mathrm{C}$, por meio da difusão em disco simples (CLSI 2009).

As cepas Lactobacillus casei subsp rhamnosus, L. paracasei, L. fermentum e L. rhamnosus foram isoladas e caracterizadas como produtoras de bacteriocinas por meio da avaliação de seu espectro de inibição, da ação de enzimas proteolíticas, como tripsina e proteases tipo VI, do efeito do $\mathrm{pH}$, da sensibilidade ao calor e clorofórmio, do tratamento com uréia, da estimação do peso molecular, do efeito bacteriostático ou bactericida segundo Pascual et al (2008). A detecção da atividade antimicrobiana das cepas de lactobacilos foi realizada pela técnica de estrias cruzadas. As cepas a serem avaliadas como produtoras foram semeadas em estria central em placas de Petri contendo ágar MRS pH 6,2 e incubadas a $37^{\circ} \mathrm{C}$ em microaerofilia durante $18 \mathrm{~h}$. O cultivo da cepa produtora foi esterilizado por exposição a vapores de clorofórmio durante 20 minutos, posteriormente cada isolado a ser testado foi semeado em linha perpendicular à cepa produtora, e incubado a $37^{\circ} \mathrm{C}$ por $18 \mathrm{~h}$, após o que se mediram os halos de inibição do crescimento bacteriano (Barberis et al., 1999).

A detecção do gene mecA foi realizada pela técnica de reação em cadeia de polimerase (PCR), a partir da extração do DNA bacteriano com o uso de lisostafina e amplificação do gene mecA segundo Coelho et al. (2007) utilizando-se os primers 5' AAA ATC GAT GGT AAA GGT TGG C 3' e 5'AGT TCT GCA GTA CCG GAT TTG C 3', e 40 ciclos de desnaturação a $94^{\circ} \mathrm{C}$ por 30s; anelamento a $55^{\circ} \mathrm{C}$ por 30 s; extensão a $72^{\circ} \mathrm{C}$ por $1 \mathrm{~min}$; um ciclo de extensão final a $72^{\circ} \mathrm{C}$ por $5 \mathrm{~min}$.

Para detecção da produção de $\beta$-lactamase foram utilizadas fitas comerciais (PROBAC do Brasil ${ }^{\circledR}$ ) em que um montante de cinco colônias foi esfregado com movimentos circulares e a formação de cor branca indicou reação positiva para produção de ß-lactamase, enquanto que a não alteração da cor indicou resultado negativo. Foram obtidos 150 isolados de Staphylococcus spp. coagulase-positivos. Mediante identificação fenotípica e genotípica das espécies, foram detectados 51 isolados de Staphylococcus aureus, dos quais 30 isolados foram submetidos a todas as etapas do presente estudo.

Na Tab. 1 apresentam-se os perfis obtidos quanto à resistência aos antimicrobianos. $\mathrm{O}$ fato de $\mathrm{o}$ antibiótico de maior eficiência ser a associação ampicilina +sulbactam aponta para a produção de betalactamases como um dos mecanismos envolvidos na resistência expressa, o que é confirmado pela detecção da produção de betalactamases, em que 96,6 \% (29/30) dos isolados foram positivos. Oito isolados (26,6\%) foram considerados multirresistentes por apresentar resistência a quatro ou mais antibióticos testados, sendo um isolado resistente a todos os antibióticos de eleição, inclusive vancomicina e oxacilina. Quatro isolados multirresistentes foram sensíveis à associação ampicilina + sulbactam, composto inibidor de beta-lactamase, sendo que um deles foi sensível apenas a esta associação. Quatro isolados foram sensíveis a vancomicina, considerada de última geração e de escolha para isolados meticilinaresistentes, dentre estes, apenas dois foram sensíveis a amoxicilina, pouco utilizado em animais de produção. Três isolados foram sensíveis a oxacilina, considerado um marcador de resistência do gênero. Estes resultados salientam a crescente disseminação de clones multirresistentes nos rebanhos bovinos.

A ocorrência de isolados resistentes a antibióticos pouco usuais na terapêutica veterinária aponta para a circulação interespecífica de genes de resistência corroborando com dados da literatura (Brown 2001; Duijkeren et al., 2004; Kaszanyitzky et al., 2004). A transmissão desses genes pode envolver tanto espécies patogênicas como membros da microbiota indígena dos hospedeiros. O gene $m e c A$ induz resistência à oxacilina e, também, acarreta falhas terapêuticas quando outros ßlactâmicos ou outras classes de antibióticos são utilizadas (Moon et al., 2007). A transferência horizontal do gene mecA em Staphylococcus spp. tem contribuído para a circulação mundial de clones oxacilina e multidroga-resistentes (Tramper-Stranders et al., 2007) e tem sido apontada como mecanismo comum de resistência a fármacos (Tramper-Stranders et al., 2007). 
Tabela 1. Perfil de resistência dos isolados de Staphylococcus aureus aos antimicrobianos de eleição (antibiotipos)

\begin{tabular}{llll}
\hline \multicolumn{2}{l}{ Perfil } & Antibióticos avaliados & $\%$ \\
\hline 1 & Resistência a um antibiótico & OXA & $3,3 \%(1 / 30)$ \\
& & PEN & $6,6 \%(2 / 30)$ \\
& & GEN & $6,6 \%(2 / 30)$ \\
& & AMP & $10 \%(3 / 30)$ \\
2 & Resistência a dois antibióticos & PEN,AMP & $3,3 \%(1 / 30)$ \\
& & OXA,PEN & $3,3 \%(1 / 30)$ \\
& & GEN,AMP & $3,3 \%(1 / 30)$ \\
& & PEN,GEN & $3,3 \%(1 / 30)$ \\
3 & Resistência a três antibióticos & PEN,AMX & $3,3 \%(1 / 30)$ \\
4 & Resistência a quatro antibióticos & OXA,PEN,AMP & $10 \%(3 / 30)$ \\
& & PAN,PEN,AMP,ASB & $3,3 \%(1 / 30)$ \\
& & OXN,GEN,AMP,AMX & $6,6 \%(2 / 30)$ \\
5 & Resistência a cinco antibióticos & OXA,PEN,GEN,AMP & $3,3 \%(1 / 30)$ \\
& & VAN,PEN,GEN,AMP,ASB & $3,3 \%(1 / 30)$ \\
6 & Resistência a seis antibióticos & OXA,VAN,PEN,GEN,AMP,AMX & $3,3 \%(1 / 30)$ \\
7 & Resistência a sete antibióticos & OXA,VAN,PEN,GEN, & $3,3 \%(1 / 30)$ \\
& & AMP,AMX,ASB & $3,3 \%(1 / 30)$ \\
8 & Não apresentou resistência & OXA,VAN,PEN,GEN,AMP,AMX,ASB & $20 \%(6 / 30)$ \\
\hline
\end{tabular}

OXA = oxacilina; PEN = penicilina; GEN = gentamicina; AMP = ampicilina; AMX = amoxicilina; VAN = vancomicina; $\mathrm{ASB}=$ ampicilina associada à sulbactam.

Na Tab. 2 apresentam-se os perfis obtidos de suscetibilidade às bacteriocinas. Dos 30 isolados de Staphylococcus aureus testados frente a quatro cepas de Lactobacillus spp. produtoras de bacteriocinas foi possível detectar sensibilidade a pelo menos uma cepa em cada um deles.

Tabela 2. Perfil de sensibilidade dos isolados de Staphylococcus aureus às bacteriocinas produzidas por Lactobacillus spp. (bacteriocinotipos)

\begin{tabular}{lll}
\hline Perfil & Bacteriocinas com atividade inibitória* & \% de S. aureus sensíveis (n=30) \\
\hline 1 & LF,LCR,LP,LR & $36,6 \%(11 / 30)$ \\
2 & LCR,LP,LR & $30 \%(9 / 30)$ \\
3 & LF,LCR,LR & $13,3 \%(4 / 30)$ \\
4 & LCR,LP & $6,6 \%(2 / 30)$ \\
5 & LF,LCR,LP & $3,3 \%(1 / 30)$ \\
6 & LF, LCR & $3,3 \%(1 / 30)$ \\
7 & LF,LP,LR & $3,3 \%(1 / 30)$ \\
8 & LF & $3,3 \%(1 / 30)$ \\
\hline
\end{tabular}

*Bacteriocinas produzidas pelas cepas: Lactobacillus fermentum (LF), L. casei susbp. rhamnosus (LCR), L. paracasei (LP), L. rhamnosus (LR).

Dentre as cepas de Lactobacillus spp. produtoras de bacteriocinas testadas, a mais eficiente foi a L23 (36,7\%), seguida por L29 (20\%), L60 $(16,7 \%)$ e L28 (6,7\%). A L23 foi purificada e está sendo caracterizada por Pascual et al. (2008), que reportaram seu amplo espectro inibitório e a importância da realização de estudos em modelos animais para melhor avaliação de sua potencial atividade antibacteriana. Uma vez que o mecanismo de ação primário das bacteriocinas, produzidas por bactérias Gram-positivas, é o da formação de poros na membrana plasmática, acarretando a perda de moléculas de baixo peso pelas células sensíveis (Pascual et al., 2008), sua atividade inibitória do crescimento bacteriano não sofre os efeitos da expressão dos mecanismos de resistência já descritos relacionados aos antimicrobianos convencionais. 
Dos 30 isolados avaliados, 70\% (21/30) foram positivos na detecção do gene mecA (Tab. 3), corroborando com a hipótese de que a expressão de proteínas ligantes de penicilina de baixa afinidade também esteve implicada como mecanismo de resistência nos isolados avaliados, não apenas para os antibióticos da classe dos beta-lactâmicos, uma vez que todos os isolados multirresistentes apresentaram este gene.
As bacteriocinas representam uma alternativa de controle biológico de bactérias resistentes, pois por não compartilhar mecanismos de ação com os antimicrobianos comercialmente disponíveis, sua atividade inibitória do crescimento bacteriano não sofre os efeitos da expressão dos mecanismos de resistência já descritos. De igual modo, os resultados obtidos apontam para um envolvimento do gene mecA com a multiresistência bacteriana.

Tabela 3. Perfil dos isolados de Staphylococcus aureus segundo a distribuição do gene mecA e produção de beta-lactamases agrupados de acordo com seus antibiotipos e bacteriocinotipos

\begin{tabular}{lcccc}
\hline Isolados & Antibiotipo & Bacteriocinotipo & mecA & Produção de $\beta$-lactamase \\
\hline 1 & 3 & 2 & + & + \\
2,16 & 2 & 1 & + & + \\
3 & 5 & 2 & + & + \\
4,17 & 3 & 1 & + & + \\
$5,10,15,18$ & 1 & + & + \\
6,13 & 1 & 2 & + & + \\
7 & 2 & 5 & + & + \\
8 & 4 & 1 & + & + \\
9 & 7 & 8 & + & + \\
11 & 4 & 4 & + & + \\
12 & 4 & 1 & + & + \\
14 & 5 & 1 & + & + \\
19 & 6 & 7 & + & + \\
20 & 2 & 2 & + & + \\
21,25 & 8 & 3 & - & + \\
22,23 & 1 & 3 & - & + \\
24 & 8 & 6 & - & + \\
26,30 & 8 & 2 & - & + \\
27 & 8 & 2 & - & + \\
28 & 4 & 2 & - & + \\
29 & 1 & 4 & & + \\
\hline$: 150$ & 1 & & + & + \\
\hline
\end{tabular}

+: isolado positivo para o teste; -: isolado negativo para o teste.

Palavras-chave: Staphylococcus aureus, mastite bovina, resistência antimicrobiana, bacteriocinas, Lactobacillus spp.

\begin{abstract}
Staphylococcus aureus is the major pathogen causing intramammary infections in dairy cattle worldwide. Among the factors that contribute to its spread and infectious potential is the ability to overcome the mechanisms of antimicrobials activity. The present work investigated the antimicrobial resistance pattern and sensibility to bacteriocins produced by strains of Lactobacillus spp of 30 isolates of S. aureus from mastitis. From this, 29 are beta-lactamase producers. Eight isolates (26.6\%) showed resistance to at least four antibiotics being considered multiresistent. All of them were mecA-positive. Otherwise, all isolates tested showed sensibility to at least one of the four bacteriocin producer strains. Due to the significant depletion of the efficacy of antimicrobials, pathogen growth inhibition by bacteriocins seems an alternative of biological control in infectious processes.
\end{abstract}

Keywords: Staphylococcus aureus, bovine mastitis, antimicrobial resistance, bacteriocins, Lactobacillus spp. 


\section{AGRADECIMENTOS}

Este estudo foi financiado por CNPq e FAPERJ (Proc. E-26/171.366/2006) e recebeu a cooperação científica do curso de Pós-graduação em Ciências Veterinárias da UFRRJ e Departamento de Microbiologia e Imunologia da Universidad Nacional del Rio Cuarto, Córdoba, Argentina.

\section{REFERÊNCIAS BIBLIOGRÁFICAS}

AARESTRUP, F.M.; SEYFARTH, A.M.; EMBORBG, H. et al. Effect of abolishment of the use of antimicrobial agents for growth promotion on occurrence of antimicrobial resistance in fecal enterococci from food animals in Denmark. Ant. Ag. Chemoth., v.45, p.20542059, 2001.

BARELLI, C.; MINTO, E.C.; MARTINEZ, R. et al. Evaluation of the antimicrobial susceptibilities of coagulase-negative staphylococci by Etest. Rev. Latinoam. Microbiol., v.41, p.67-72, 1999.

BROWN D.F.J.; YATES V.S. Detection of methicillin/oxacillin resistance in staphylococci. J. Antibiot. Chemother., v.48, p.65-70, 2001.

CLINICAL and laboratory standards institute. Performance standards for antimicrobial disk susceptibility tests. Approved standards. CLSI document M2-A3. Clinical and Laboratory Standards Institute, Wayne, Pa, 2006

COELHO, S.M.O.; MENEZES, R.A.; SOARES, L.C. et al. Mapeamento do perfil de resistência e detecção do gene mecA em Staphylococcus aureus e Staphylococcus intermedius oxacilinaresistentes isolados de espécies humanas e animais. Cienc. Rural, v.37, p.195-200, 2007.

DUIJKEREN, E.V.; BOX, A.T.A.; HECK, M.E.O.C. et al. Methicillin-resistant staphylococci isolated from animals. Vet. Microbiol., v.103, p.91-97, 2004.
KASZANYITZKY, E.J.; EGYED, Z.; JANOSI, $S$. et al. Staphylococci isolated from animals and food with phenotypically reduced susceptibility to beta-lactamase-resistant betalactam antibiotics. Acta Vet. Hung., v.52, p.7-17, 2004.

KONEMAN, E.W.; ALLEN, S.D.; JANDA, W.M. et al. Diagnóstico Microbiológico. 5.ed. Rio de Janeiro: MEDSI, 2008. 1465p..

MOON, J.S.; LEE, A.R.; KANG, H.M. et al. Phenotypic and genetic antibiogram of methicillin-resistant staphylococci isolated from bovine mastitis in Korea. J. Dairy Sci., v.90, p.1176-1185, 2007.

MORAES, A.P.R.; BADINI, P.V.; SOUZA, M.M.S. et al. Avaliação da capacidade de Stomoxys calcitrans (Linnaeus, 1758) em carrear bactérias envolvidas nas etiologias das mastites de municípios do Rio de Janeiro. Rev. Bras. Parasitol. Vet., v.13, p.143-149, 2004.

PASCUAL L.M.; DANIELE M.B.; GIORDANO W. et al. Purification and partial characterization of novel Bacteriocin L23 Produced by Lactobacillus fermentum L23. Curr. Microbiol., v.56, p.397-402, 2008.

TRAMPER-STRANDERS, G.A.; VAN DER ENT, G.K.; GERRITSEN, S.A.M. et al. Macrolide-resistant Staphylococcus aureus colonization in cystic fibrosis patients: Is there transmission to household contacts? J. Antibiot. Chemother., v.60, p.665-668, 2007.

ZÁRATE, G.; NADER-MACIAS, M.E. Influence of probiotic vaginal lactobacilli on in vitro adhesion of urogenital pathogens to vaginal epithelial cells. Lett. Appl. Microbiol., v.43, p.174-180, 2007. 